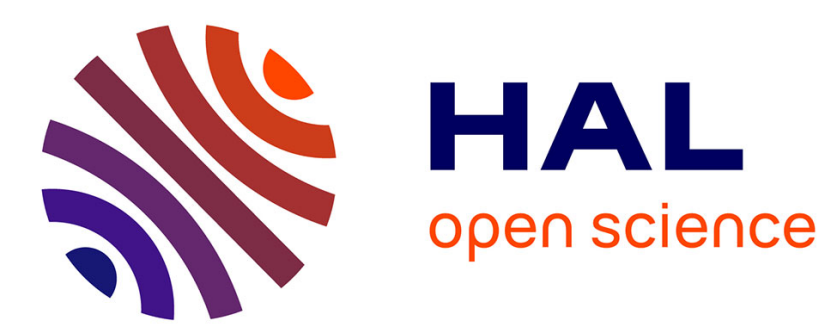

\title{
Improved on-chip impedimetric immuno-detection of subpopulations of cells toward single-cell resolution
}

\author{
Remi Manczak, Marc Fouet, Rémi Courson, Paul-Louis Fabre, Armelle
}

Montrose, Jan Sudor, Anne Marie Gué, Karine Reybier

\section{To cite this version:}

Remi Manczak, Marc Fouet, Rémi Courson, Paul-Louis Fabre, Armelle Montrose, et al.. Improved onchip impedimetric immuno-detection of subpopulations of cells toward single-cell resolution. Sensors and Actuators B: Chemical, 2016, 230, pp.825-831. 10.1016/j.snb.2016.02.070 . hal-01305407

\section{HAL Id: hal-01305407 \\ https://hal.science/hal-01305407}

Submitted on 22 Apr 2016

HAL is a multi-disciplinary open access archive for the deposit and dissemination of scientific research documents, whether they are published or not. The documents may come from teaching and research institutions in France or abroad, or from public or private research centers.
L'archive ouverte pluridisciplinaire HAL, est destinée au dépôt et à la diffusion de documents scientifiques de niveau recherche, publiés ou non, émanant des établissements d'enseignement et de recherche français ou étrangers, des laboratoires publics ou privés. 
4 Rémi MANCZAK ${ }^{a, b}$, Marc FOUET ${ }^{b}$, Rémi COURSON ${ }^{b}$, Paul-Louis FABRE ${ }^{a}$, Armelle 5 MONTROSE ${ }^{a}$, Jan SUDOR ${ }^{a}$, Anne-Marie GUE $^{b, \S}$, Karine REYBIER $^{a, \S}$ *

6

7

${ }^{\text {a }}$ Pharma-Dev, UMR 152, Université de Toulouse, IRD, UPS, France

${ }^{b}$ LAAS-CNRS, 7 avenue du Colonel Roche, F-31077 Toulouse cedex 4, France

9

$\S$ These authors contributed equally to the work.

*Corresponding authors: Faculté des Sciences Pharmaceutiques, Université Paul Sabatier

Toulouse 3, 35 chemin des Maraîchers, 31069 Toulouse cedex 9, France tel: +33 562259804; fax: +33 562259802, karine.reybier-vuattoux@univ-tlse3.fr 


\section{ABSTRACT}

3 Impedance spectroscopy has gained interest for the quantitative detection of specific cells mainly 4 due to a label-free detection and their miniaturization capability required for integration on chip and 5 development of point-of-care diagnostics. In this paper, we report the study of impedimetric 6 microfluidic devices with improved sensitivity targeting the immuno-detection of cells. The sensitivity 7 of our system was evaluated in terms of the capacity of the electrodes to trap monocytes by 8 immune-reaction with CD14 antibody immobilized on micro-electrode surface. All measurements 9 were performed in faradic mode using a redox probe. The sensitivity was evaluated as a function of the impedance increase $\Delta Z$ recorded at $100 \mathrm{~Hz}$ caused by the insulating character of the cell trapped on electrodes. Analyses first confirmed that the sensing performances were significantly improved by using microfluidic. This increase could originate from an increase in the probability of cell trapping and a better organization of cells on the electrode due to the laminar flow. The great sensitivity was recorded with interdigitated electrodes for which the influence of the gap value was evaluated. The maximum sensitivity was reached with the smallest inter-electrodes gap tested $(50 \mu \mathrm{m})$. This performance was in part attributed to the redox cycling taking place between neighboring fingers that was strongly affected when cells were trapped on the electrodes edges. Furthermore we also demonstrate that the slice of cell concentration for which the sensitivity is maximized is correlated to the area of electrodes. Moreover, the smallest area of interdigitated electrode $(0.1 \mathrm{~mm}$ length) allowed the detection of as low as 5 cells per $\mathrm{mL}$

\section{KEYWORDS:}

Impedance, interdigitated electrode, microfluidic, immune-detection, cell detection 


\section{INTRODUCTION}

The quantitative detection of specific cells is usually carried out by flow cytometry due to its high sensitivity and reliability. Fluorescence-activated cell sorting (FACS) analysis which combines fluidic techniques and optics is the reference method used to count cells via fluorescently labeled antibody conjugates. However, this technique is time-consuming, expensive and not suited to routine screening and point-of-care diagnostics. The development of total analysis solutions in microfluidic or lab on-chip devices for integrated cell-based detection increased considerably over last ten years [1]. Miniaturized cell detection devices have several advantages such as rapid detection, low cost, use of small volumes of biological materials, portability and improved sterile conditions. The most widely used techniques for cell counting are optical techniques [2,3] (fluorescence, surface plasmon resonance, interferometric detection) or electrical methods [4,5]. Electrochemical methods have gained interest mainly due to a label-free detection and their miniaturization capability required for integration on a chip, but also for their low cost and short analyses times. Among electrochemical methods, Impedance is a powerful electrochemical method that uses periodic small AC amplitudes and responds to modifications caused by the target cells (coulter counter for single cell analysis) [68]. Electrochemical impedance spectroscopy (EIS) is the method of choice in the case of cells trapped on functionalized electrodes surface. In this latter case, the change in the electrode impedance is measured and can be correlated to the amount of trapped cells [9]. Bio-impedance monitoring has already been employed for example to study cellular kinetics [10], cancer drug screening [11], or parasitized cells [12-14].

Electrochemical measurements rely on the use of at least 2 electrodes. Currently, combination with microfabrication-based technologies allows fabrication of micron-sized electrodes. Microelectrodes have many advantages over conventional electrodes among which economy due to batch fabrication [15], large current densities (low currents) due to enhanced mass transport [16], very short time constants, low ohmic drop and possibility of integration and the development of portable systems [17]. Microelectrodes, due to smaller currents, have higher impedances [18] and allow the study of high resistivity samples [19]. Furthermore, the spatial resolution of microelectrodes offers the ability to explore several cells [20] or even a single cell [21]. The measured impedance response is

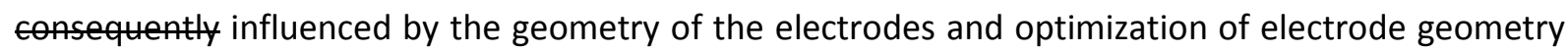
is a key factor in cell analysis as demonstrated by the number of paper dealing with this subject $[18,22,23]$. Furthermore the sensing performance can be significantly improved by using microfluidics to provide effective liquid manipulation and greater flexibility.

In this paper, we report the study of impedimetric microfluidic devices with improved sensitivity targeting the immuno-detection of cells. The sensitivity of the system was evaluated as the capacity of the electrodes to trap monocytes by immune-reaction with CD14 antibody immobilized on the electrode surface [13] and to produce a significant impedance change. Several designs including simple or interdigitated electrodes were tested and also compared to microfluidic measurements.

\section{MATERIALS AND METHODS}

\subsection{Materials}

\subsubsection{Products}


6-mercapto-1-hexanol (MH), 11-mercaptoundecanoic acid (MUA), N-ethyl-N-(dimethylaminopropyl)carbodiimide (EDC), N-hydroxysuccinimide (NHS), phosphate buffered saline (PBS) solution, recombinant protein $G(P G)$, bovine serum albumin (BSA), lipopolysaccharide (LPS), hydrogen peroxide and sulfuric acid were purchased from Sigma-Aldrich (Saint-Quentin Fallavier, France). The CD 14 and CD 16 antibodies were purchased from Miltenyi Biotec (Paris, France). Absolute ethanol was purchased from Fisher Scientific (Illkirch, France) and deionized water was obtained using the Milli-Q water system Millipore (Molsheim, France). DF-1050 films (Engineered Materials Systems, Inc.), SU8 3050 resin (Microchem), 4" glass substrates (Schott AF32), Polydimethylsiloxane (PDMS) (Dow corning), hexamethyldisiloxane (HMDS) (Sigma Aldrich), and AZ Nlof 2035 (AZ Electronic Materials) were used for the microfluidic device.

\subsubsection{Monocyte cell culture}

Monocytes (THP-1) were cultivated in Roswell Park Memorial Institute 1640 medium (RPMI 1640; Sigma-Aldrich) supplemented with sodium bicarbonate (1.5 g/L; Lonza (Amboise, France)), d-(+)glucose (4.5 g/L; Sigma-Aldrich), L-glutamine ( $2 \mathrm{mM}$; Lonza), sodium pyruvate (1mM; Sigma-Aldrich), 4-(2-Hydroxyethyl)-1-piperazineethanesulfonic acid (10 mM; Sigma-Aldrich), 2-mercaptoethanol ( $0.05 \mathrm{mM}$; Sigma-Aldrich) and $10 \%$ foetal bovine serum (Lonza). The cells were maintained at $37^{\circ} \mathrm{C}$ in a $5 \% \mathrm{CO}_{2}$ atmosphere.

The cell suspensions were prepared par dilution successives et comptage sur??

\subsection{Methods}

\subsubsection{Devices manufacturing process}

Devices were manufactured on glass substrates combining standard microfabrication processes (electrodes) and thick photoresists technologies (microfluidics).

\section{Microelectrodes fabrication (Figure 1a)}

The glass substrates were first cleaned with a piranha solution to remove any organic residues. After rinsing with deionized water, drying under a nitrogen flow, and exposure to an $\mathrm{O}_{2}$ plasma (Tepla 600 ), the substrate was treated with hexamethyldisiloxane (HMDS) to improve adhesion of photolithographic resists. The structuration of gold electrodes was processed following a classical "lift off" technique. An AZ Nlof 2035 resist was spin-coated at "vitesse" and exposed to UV (635nm) during "durée" with a "masqueur utilise". Than a titanium-gold layer respectively 50nm and $200 \mathrm{~nm}$ thick was obtained by evaporation in a "marque machine" reactor.i. After the photoresist revelation in acetone, the patterned gold layer was then covered with a $5 \mu \mathrm{m}$ thick SU-8 photoresist (Microchem) . SU-8 was spin coated at "vitesse" during "durée" and prebaked (PEB) at "temperature" during "durée". The SU-8 was patterned using standard photolithography in order to cover electric tracks and to protect electrodes periphery. This step allows to control precisely the electrodes geometry and dimensions and to avoid unexpected electrochemical effects at the Ti/Au interface. The last residues of unexposed resins were removed by $\mathrm{O}_{2}$ plasma.

\section{Microfluidic integration (Figure 1b)}

Microfluidic channels were patterned by standard lithography of a $100 \mu \mathrm{m}$ thick SU8 layer deposited on top of the electrodes wafer. As described extensively in Abgrall et al (ref) open channels were 
then covered by lamination of a $25 \mu \mathrm{m}$ thick "home-made" dry film of SU-8 and a final photolitographic step allowed the realization of microfluidic inlets and outlets. To reduce phenomenon of cracks and delamination of the layer originating from residual stress in the SU-8 photoresist, a $120^{\circ} \mathrm{C}$ hard bake was then applied to the system.

Fluidic connections were obtained either with the help of PDMS pads glued at each inlet/outlet of the channels or with a mechanical support especially designed to handle the fluid and power supplies of each chip. PDMS pads were obtained with Polydimethylsiloxane (PDMS) mixed with curing agent at proportion of $10 / 1$, degassed with nitrogen for $1 \mathrm{~h}$, then coated on a clean silicon master, and finally, annealed at $90{ }^{\circ} \mathrm{C}$ in an oven during $1 \mathrm{~h}$. After 15 min exposure to an $\mathrm{O}_{2}$ plasma, the pads were sticked onto the wafer using a UV-sensitive glue.

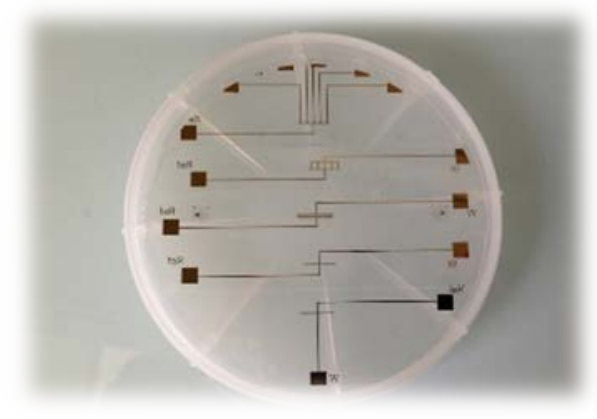

a

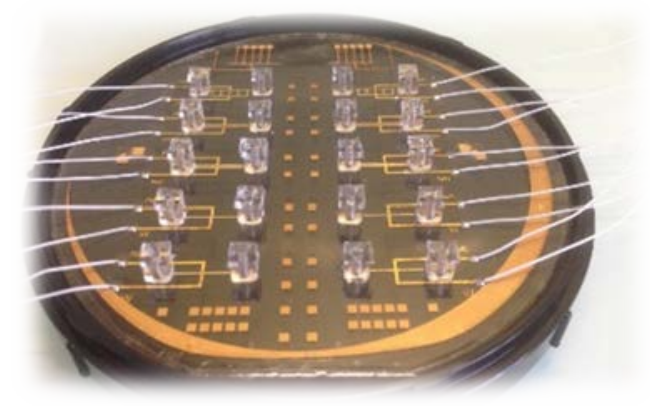

b

Figure 1: pictures of the devices built for the study a) without and b) with microfluidic channels and PDMS pads allowing circulation of fluids.

To reduce fabrication time and cost the SU- 8 resist was also replaced by a novel epoxy dry film DF1050 (EMS) following the process described by Courson et al. [24]. Note that in this latter case the mechanical support was used exclusively.

Finally, the wafer was diced using a diamond pen to individualize each microelectrode system.

\subsubsection{Electrode modification}

The cleaned electrodes were modified as described by Montrose et al. [13]. In absence of channels the surfaces were modified through successive deposition of drops of the modifying agents for various incubation times: a mixture of 11-mercaptoundecanoïc acid (MUA) $1 \mathrm{mM}$ and 6mercaptohexanol (MH) $10 \mathrm{mM}$ for $18 \mathrm{~h} /$ a mixture of aqueous solutions of $\mathrm{N}$-hydroxysuccinimide (NHS) $15 \mathrm{mM}$ and 1-Ethyl-3-(3-dimethylaminopropyl-carbodiimide (EDC) $75 \mathrm{mM}$ for $30 \mathrm{~min} /$ protein G 100 g.mL $\mathrm{mL}^{-1}$ in PBS $10 \mathrm{mM}$ for $18 \mathrm{~h} / \mathrm{BSA} 143 \mathrm{~g} / \mathrm{L}$ for $30 \mathrm{~min}$ and CD14 antibody X mM for 18h. In the case of microfluidic devices the modification of electrodes were carried out under a flow of the modifying agents using a Fluigent ${ }^{\circledR}$ MFCS- $8 \mathrm{C}$ with an inlet pressure of $10 \mathrm{mbar}$ and no outlet pressure for different times : SAMs: 3 hours / NHS EDC: $30 \mathrm{~min} / \mathrm{PG}: 3 \mathrm{~h} / \mathrm{BSA}: 30 \mathrm{~min} / \mathrm{Ab}: 2 \mathrm{~h}$. This procedure considerably reduced the time of the surface bio-functionalization to about 10 hours.

\subsubsection{Impedimetric measurements}

The cell trapping were carried out, either by placing a drop of cells suspension during 2 hours on functionalized electrodes in the case of non-microfluidic devices or by applying a continuous flow of 
cells suspensions for $30 \mathrm{~min}$ in channels (pressure drop of $10 \mathrm{mbar}$ ) before rinsing and impedance measurements.

EIS measurements were performed using an Autolab PGSTAT 128n (Metrohm) and the NOVA software. Experiments were performed in PBS $10 \mathrm{mM}(\mathrm{pH}=7.4)$ containing $5 \mathrm{mM} \mathrm{Fe} / \mathrm{Fe}$ $\left(\mathrm{Fe}(\mathrm{CN})_{6}^{3-/ 4-}(1: 1)\right)$. The impedance spectra were recorded from $100 \mathrm{mHz}$ to $50 \mathrm{kHz}$ at the free potential with an alternating voltage of $10 \mathrm{mV}$. All experiments were performed at room temperature in a Faraday cage.

In the case of open chips, the electrochemical measurements were performed in a drop of electrolyte containing the redox probe using a SCE as reference immerged in the drop (scheme $1 \mathrm{~b}$ ). In the case of microfluidic chips, the measurements were performed under a flow of electrolyte, using a two electrode set-up, the reference and counter electrode being short-cut.

\section{RESULTS AND DISCUSSION}

Previous experiments performed on macro-electrodes with different areas $\left(1,0.5,0.04 \mathrm{~cm}^{2}\right)$ have demonstrated a strong increase in sensitivity when decreasing electrodes areas $190 \%$ of improvement in $\Delta Z$ for $0.04 \mathrm{~cm}^{2}$ area compare to $1 \mathrm{~cm}^{2}$ ) without any increase in the noise [13]. This is in agreement with inverse proportionality between charge transfer resistance and the electrode area. For this reason we decided to miniaturize working and counter electrodes using classical technologies of microfabrication such as photolitography associated with lift off. Three geometries of micro-electrode arrays were tested: simple, multiple and interdigitated electrodes as presented in scheme 1a.

\subsection{Static measurements}

In order to qualify micro-electrodes behavior, static measurements were first performed. In this case, both biofunctionalization of electrodes and impedimetric measurements were carried out using drops as illustrated in Scheme 1b. The functionalization of electrodes with specific antibodies CD14 was carried out using self-assembled monolayers associated with protein $\mathrm{G}$ as previously described in the literature [13]. Each modification step was characterized using electrochemical impedimetric spectroscopy (data not shown). It was verified by applying the modification procedure to SU8 surface that none of the reagents reacts with the resins surface. To study the sensitivity of the immunosensor, monocyte concentrations ranging from $10^{3}$ to $10^{9}$ cells $/ \mathrm{mL}$ were first deposited on each microelectrode of various geometry previously functionalized with CD14 antibody. The corresponding Nyquist diagrams are presented in Figure 2a-c. The semi-circle diameter increases with the cell concentration due to the insulating character of cells which cover the electrodes and block efficiently the electron transfer towards the redox probe. The maximum variations of impedance were recorded at low frequency at $100 \mathrm{~Hz}$ (data not shown) demonstrating that the diffusion of the redox probe was also modified by the presence of cells [25]. The variations of impedance relative to the antibody layer $\left(\Delta Z_{/ A B}=Z-Z_{A B}\right)$ measured at $100 \mathrm{~Hz}$, as a function of the logarithm of cells concentrations are presented in Figure $2 \mathrm{~d}$. One can consider that the impedance measured is the sum of the signal corresponding to the free and graft parts of the surface, which means that the impedance is related to the surface coverage ratio. A free surface presents the lowest impedance change $\Delta Z_{/ A B}=0$ while a totally covered surface would present the highest one, $\Delta Z_{/ A B}$ max. The best sensitivity was recorded with simple electrodes in particular in the range of $10^{3}$ and $10^{5}$ 
cells $/ \mathrm{mL}$ with a sensitivity $\Delta \mathrm{Z}_{\text {/AB }}=800 \Omega /$ decade. The sensitivity was decreasing when the electrode surface increases to reach $\Delta Z_{/ A B}=200 \Omega /$ decade for multiple and interdigitated electrodes for the same range. The graph clearly demonstrates different profiles of sensitivity depending on the geometry; the impedance for electrodes having the smallest surface areas seems to saturate as when totally covered, whereas for electrodes with large areas, impedances increase exponentially with increasing concentrations of cells. The difference between simple and multiple electrodes can be easily explained by considering that the multiple electrodes corresponds to electrodes in parallel and in this case their impedance is given by $: 1 / Z=\Sigma(1 / Z i)$. The impedance of multiple electrodes would be equal to $Z_{\text {simple }} / 5$. Furthermore one can note that impedances recorded with interdigitated electrodes were weaker than impedances recorded with other electrode types. This result could be explained by the hemi-spherical diffusion field at each interdigitated microelectrode overlapping with neighboring diffusion layers [26], and the concomitant redox cycling between electrode fingers enhancing the current and then decreasing the impedance.

a)

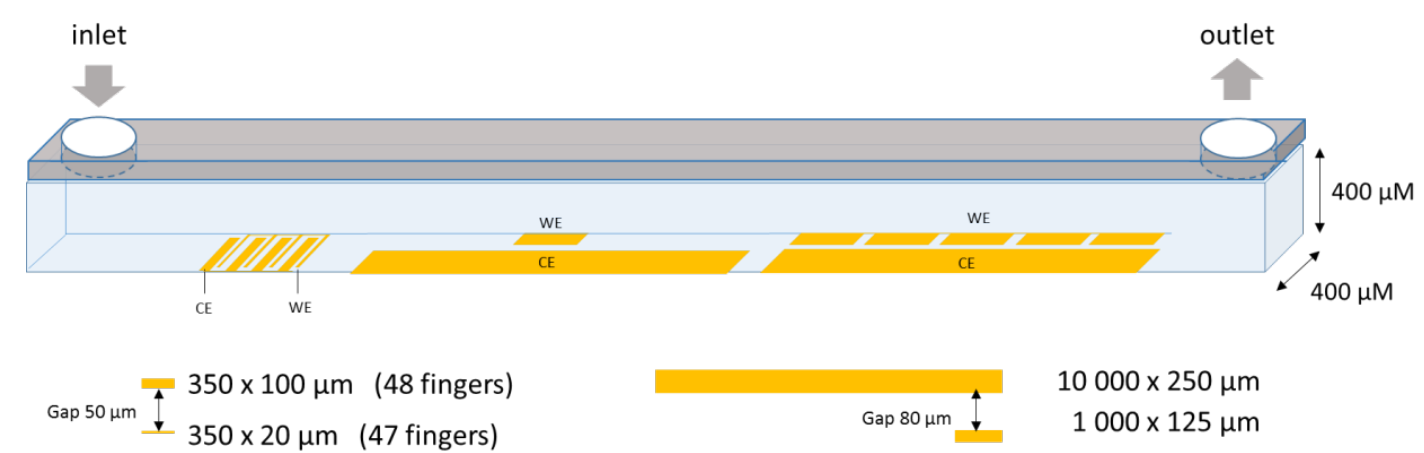

b)
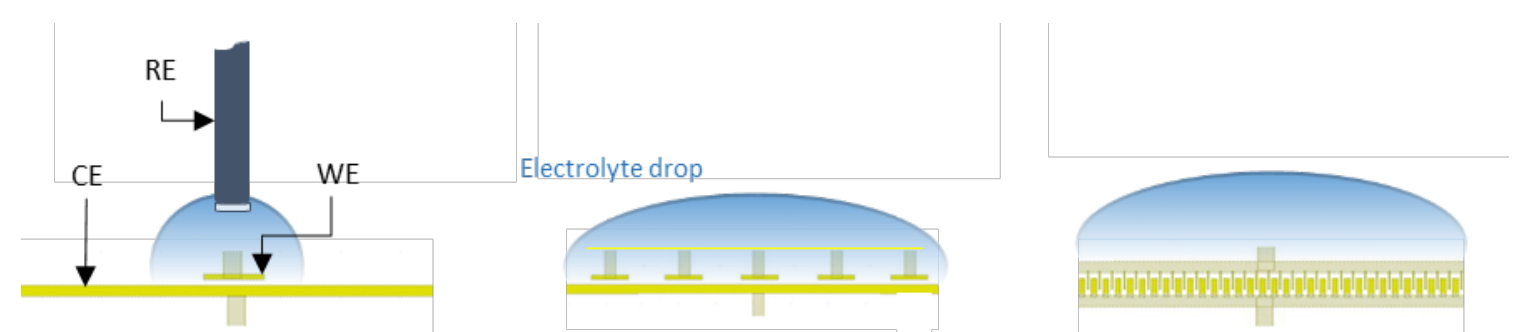

Scheme 1: a) three electrode geometries tested; b) impedimetric measurements were carried out through deposition of drops and immersion of the SCE reference electrode.

a

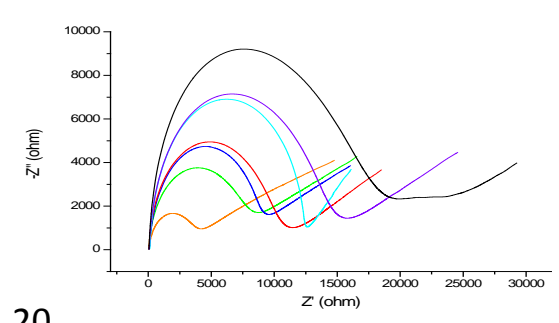

b

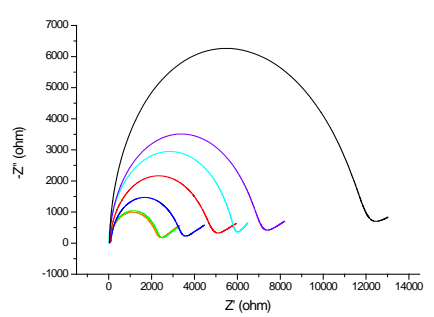

c

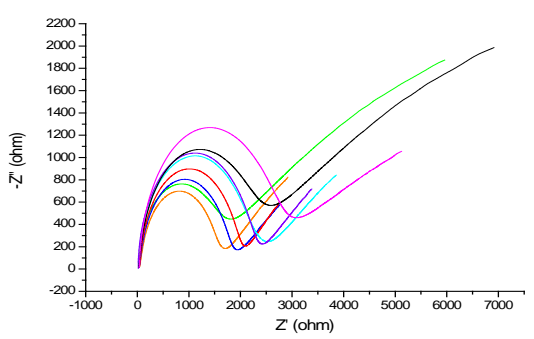




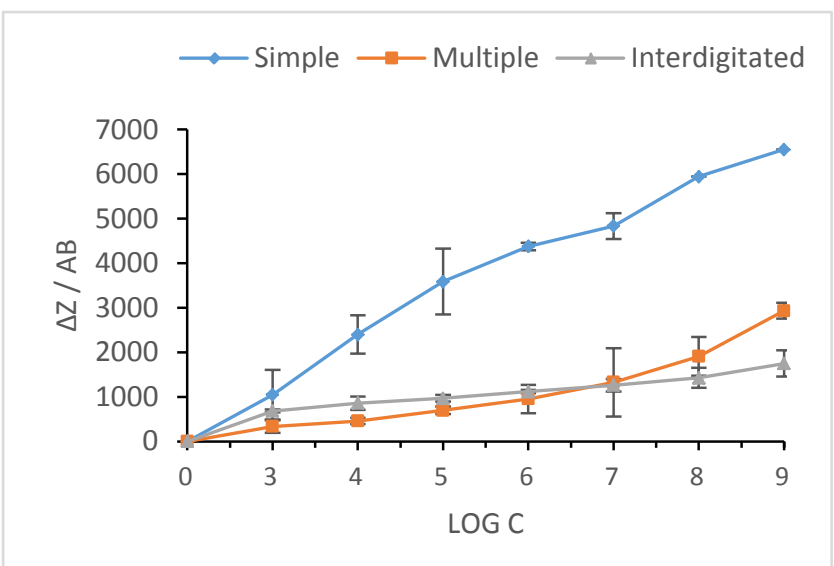

Figure: 2- Influence of the electrode geometry in static mode. Nyquist plot of CD 14 antibody modified electrodes, after incubation with monocytes suspensions $\left(0(-), 10^{3}(-), 10^{4}(-), 10^{5}(-), 10^{6}\right.$ $(-), 10^{7}(-), 10^{8}(-), 10^{9}(-)$ cells $\left./ \mathrm{mL}\right)$ measured in $5 \mathrm{mM} \mathrm{K} \mathrm{K}_{3}\left[\mathrm{Fe}(\mathrm{CN})_{6}\right] / \mathrm{K}_{4}\left[\mathrm{Fe}(\mathrm{CN})_{6}\right]$ for (a) simple, (b) multiple, and (c) interdigitated microelectrode. Frequency range: $0.1 \mathrm{~Hz}$ to $50 \mathrm{kHz}$. d) Corresponding variation of impedance relative to the antibody layer measured at $100 \mathrm{~Hz}$, as a function of the logarithm of cells concentrations.

We are aware that our static system consisting of a drop of cell suspension siting on the microelectrodes is not ideal as the interaction of cells with a functionalized surface takes place mainly through sedimentation. Taking into account the radius of the sample drop (around $3 \mathrm{~mm}$ for $200 \mu \mathrm{L}$ of electrolyte) and a sedimentation speed of cells of around $1 \times 10^{-6} \mathrm{~m} / \mathrm{s}$, the fraction of cells reaching the modified surface within 2 hours is weak. For example for $10^{6}$ cells $/ \mathrm{mL}$ i.e. 200000 cells in the drop, only 600 will be trapped on a single-electrode while the full coverage is reached for 1000 cells (cell radius estimated to $12 \mu \mathrm{m}$ ). This low trapping ratio explained why the saturation appear for very high cell concentrations. Furthermore, trapping through sedimentation favors the non-specific grafting leading to not well organized layers and stacking.

\subsection{Microfluidic approach}

Microfluidic integration offers numerous advantages compared to static approach. Beyond wellestablished potentialities of fluid handling, such as sample pretreatment, assays parallelization and others, in our case it also minimizes the sedimentation phenomenon and increases specific cellelectrodes interaction.

We manufactured microfluidic devices with channels (length: $14800 \mu \mathrm{m}$, width: $500 \mu \mathrm{m}$, height: 100 $\mu \mathrm{m})$ and integrated electrodes of different designs. The surface of electrodes was functionalized inside assembled chips, which strongly shortened the functionalization time to only 10 hours and dramatically improved the homogeneity of the attached layers.

The impedimetric analyses were performed using a two electrodes set-up including a pseudo [counter + reference] electrode. The cell trapping was performed by applying a continuous flow of cells suspensions for $30 \mathrm{~min}$ on functionalized electrodes. After rinsing the electrodes, the impedance measurements were then performed under a flow of the PBS electrolyte containing the redox probe. The Nyquist diagrams and the corresponding variations of impedance recorded at $100 \mathrm{~Hz}$ for are presented for each geometry in Figure $3 \mathrm{a}$ and $3 \mathrm{~b}$ respectively. The microfluidic mode induced a transition to a stationary mode (semi-infinite diffusion) characterized as demonstrated on diagrams by the apparition of dissymmetric loops of Leminscate type for all geometries (Figure 3a) instead of 
the classical Warburg line recorded in static mode. The values of the impedance changes $\Delta \mathrm{Z}_{/ A B}$ recorded in this case are much greater than the ones recorded in the static mode. The variation of impedance $\Delta Z$ increases for $10^{6}$ cells $/ \mathrm{mL}$ by a factor 2,12 and 18 for simple, multiple and interdigitated electrodes respectively. This increase could originate from different factors, including an increase in the probability of cell trapping and a better organization of cells on the electrode due to presence of a laminar flow, and the change of the measuring mode from three to two electrodes. For interdigitated electrodes the sensitivity increased from 200 to $4000 \Omega$ per log[cells], making this geometry the most sensitive in the microfluidic mode. This could originate from the fact that interdigitated electrode structures distribute the detection of localized changes to a larger sensing surface [27] (length 20 times larger than for simple electrodes). Furthermore, the trapping of cells on electrode edges modifies the inter-electrode space and consequently, the conductivity between electrodes has even stronger impact on the impedance when the distance between the electrodes is small. This can explain the great impedance changes recorded for interdigitated electrodes having a gap of $50 \mu \mathrm{m}$ compared to the others with a gap of $180 \mu \mathrm{m}$. These results are in accordance with the works of Couniot and co-workers [28] which have demonstrated (using bacteria) a correlation between the interdigitated inter-electrode space and the detection sensitivity. The mean sensitivity is indeed larger for smaller electrode gaps but the electrical response is noisier. They established that the optimal electrode gap is approximately four times the bacteria diameter [28].
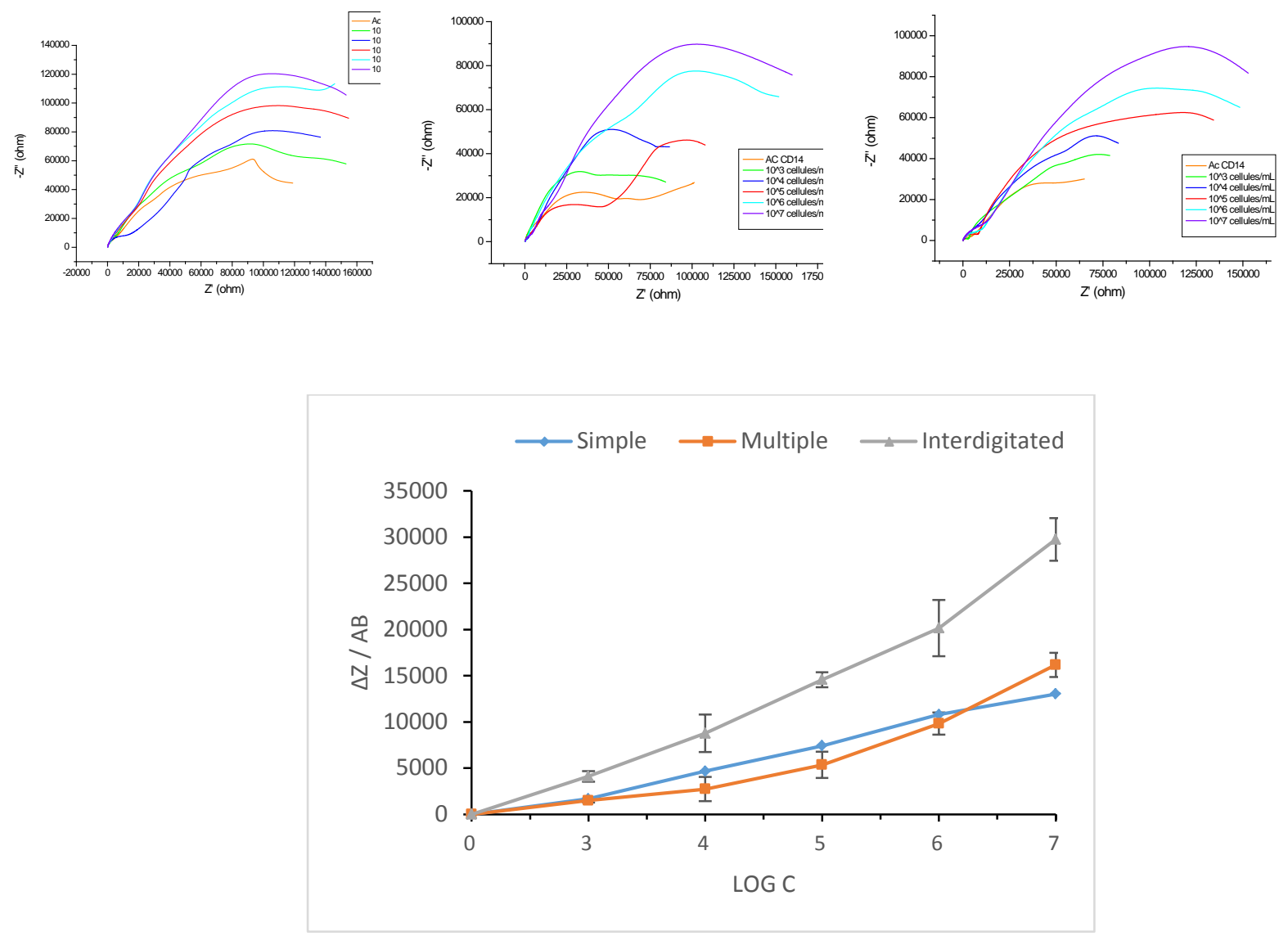

Figure 3- Influence of the electrode geometry in microfluidic mode ; Nyquist plot of CD 14 antibody modified electrodes, after incubation with monocytes suspensions $\left(0(-), 10^{3}(-), 10^{4}(-), 10^{5}(-), 10^{6}\right.$ $(-), 10^{7}(-), 10^{8}(-), 10^{9}(-)$ cells $\left./ \mathrm{mL}\right)$ measured in $5 \mathrm{mM} \mathrm{K} \mathrm{K}_{3}\left[\mathrm{Fe}(\mathrm{CN})_{6}\right] / \mathrm{K}_{4}\left[\mathrm{Fe}(\mathrm{CN})_{6}\right]$ for (a) simple, (b) multiple, and (c) interdigitated microelectrode. Frequency range: $0.1 \mathrm{~Hz}$ to $50 \mathrm{kHz}$. Corresponding 
variation of impedance relative to the antibody layer measured at $100 \mathrm{~Hz}$, as a function of the logarithm of cells concentrations for measurements carried out in a microfluidic mode with different geometries.

Therefore, 3 different gap values were tested: 50, 60 and $75 \mu \mathrm{m}$. After functionalization of the electrodes, a range of cell concentration of $10^{3}$ to $10^{6}$ cells $/ \mathrm{mL}$ was applied on each interdigitated design. The corresponding variations of the relative impedance module $\Delta \mathrm{Z}_{/ \mathrm{AB}}$ as a function of the logarithm of cell concentrations are presented in Figure 4 . The results clearly demonstrate that the sensitivity increases when the gap decreases. The sensitivity recorded on the range tested varies from $1280 \Omega$ /decade for the gap of $75 \mu \mathrm{m}$ to $2200 \Omega$ /decade for $60 \mu \mathrm{m}$ and $4111 \Omega$ /decade for the gap of $50 \mu \mathrm{m}$. These results are in accordance with the factor 4 between the gap and the scale of the target cell mentioned in literature [28], assuming that the diameter of monocytes used (THP1) varies around $12-13 \mu \mathrm{m}$.

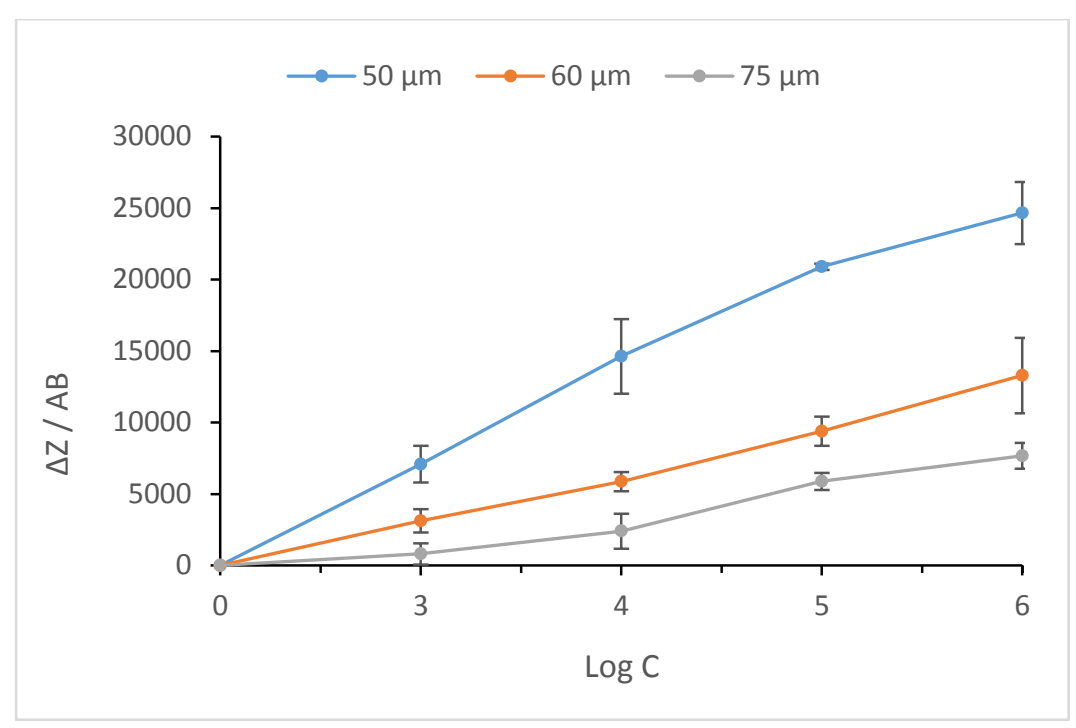

Figure 4: Influence of the gap. Variation of impedance relative to the antibody layer measured at 100 $\mathrm{Hz}$, as a function of the logarithm of cells concentrations for measurements carried out in a microfluidic mode with interdigitated electrodes for different values of gap: 50, 60 and $75 \mu \mathrm{m}$.

Another parameter has to be taken into account and it concerns the area of the electrode and more specifically the length and number of strands. Four different lengths were tested: $0.1,0.5,1$ and 3 $\mathrm{mm}$ which comprise respectively 1, 2, 4 and 14 fingers of same dimension $(20 \mu \mathrm{m} \times 350 \mu \mathrm{m})$ with a given gap equal to $50 \mu \mathrm{m}$. For this study, the fabrication process was slightly modified by replacing SU8 resin by laminated DF films to reduce processing time. Furthermore, to overcome micro-welds and PDMS bonding pads allowing microfluidic circulation of fluids, a new measurement system was set up at LAAS. Both electrical and fluidic parts were managed by the mechanical support, in which each chip was incorporated to be tested individually. The corresponding variations of the impedance module are presented in Figure 5. According to the surface, it is clearly observed that for the $0.1 \mathrm{~mm}$ a rapid saturation due to a total coverage appear while for the $3 \mathrm{~mm}$ (surface ratio 14), the $\Delta \mathrm{Z}_{\text {/AB }}$ increases continuously with cell concentration due to a partial coverage. The two others systems present intermediate behaviors: an increase of the signal tending to saturate. All interdigitated size have comparable maximum sensitivities ( $>6000 \Omega$ /decades) but for specific cell concentration range. The $0.1 \mathrm{~mm}$ electrode has a maximum sensitivity until $10^{2}$ cells, and after that the sensitivity 
decreases due to the surface saturation. Furthermore with this area the device allowed a detection limit below 5 cells $/ \mathrm{mL}$ ( $L O D=3 \times \mathrm{SD} / \mathrm{slope}$ ). For the $0.5 \mathrm{~mm}$ microelectrode, the sensitivity is maximum in a cell concentration ranging from $10^{2}$ to $10^{5}$ cells $/ \mathrm{mL}$ and $10^{6}$ for $1 \mathrm{~mm}$ electrodes before it starts to decrease. In the case of $3 \mathrm{~mm}$ electrode, the sensitivity increases from $10^{5}$ cells $/ \mathrm{mL}$. These results demonstrate that there is a threshold beyond which a surface is exploitable for a given slice of concentration. A too large area is not suitable to detect rare events. For early diagnostic i.e. detection of low number of cells, the $0.1 \mathrm{~mm}$ microelectrode seems to be the most suitable.

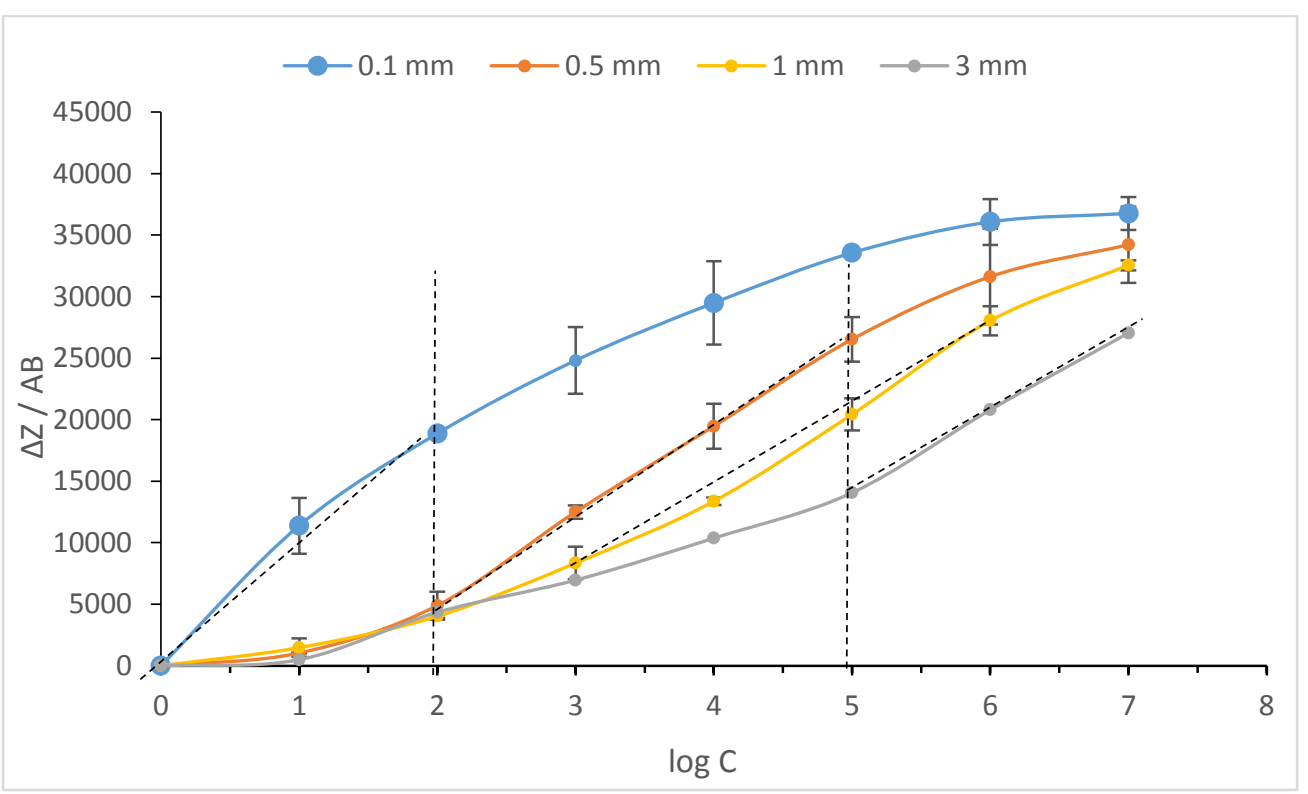

Figure 5: Influence of the electrode length. Variation of impedance relative to the antibody layer measured at $100 \mathrm{~Hz}$, as a function of the logarithm of cells concentrations for measurements carried out in a microfluidic mode with interdigitated electrodes for different lengths: 0.1, 0.5, 1 and $3 \mathrm{~mm}$ (surface ratio $1,2,4$ and 14).

\section{CONCLUSION}

In this paper we demonstrate by employing monocytes, how the immunodetection of subpopulations of cells is strongly enhanced by using interdigitated electrodes with small interelectrodes gap compared to electrodes with simple geometries. These performances are linked to strong minimization of the redox cycling between electrode fingers upon cell trapping. Furthermore we also demonstrate that the slice of cell concentration for which the sensitivity is the maximum is proportional to the electrode size. Moreover, the interdigitated electrodes with smallest area that were fabricated $(0.1 \mathrm{~mm}$ length) allowed to detect cells in solutions with concentrations smaller than 5 cells $/ \mathrm{mL}$, opening thus new perspectives for the detection of rare events such as the tracking of circulating stem cells, for example.

\section{ACKNOWLEDGEMENTS}


The authors would like to thank the Région Midi-Pyrénées and the University of Toulouse for financial support.

\section{REFERENCES}

[1] H. Andersson, A. Van den Berg, Microfluidic devices for cellomics: a review, Sensor. Actuat. BChem. 92 (2003) 315-325.

[2] S.Y. Yang, S.K. Hsiung, Y.C. Hung, C.M. Chang, T.L. Liao, G.B. Lee, A cell counting/sorting system incorporated with a microfabri cated flow cytometer chip, Meas. Sci. Technol. 17 (2006) 2001-2009.

[3] C.C. Lin, A. Chen, C.H. Lin, Microfluidic cell counter/sorter utilizing multiple particle tracing technique and optically switching approach, Biomed. Microdevices 10 (2008) 55-63.

[4] K. Kiilerich-Pedersen, N. Rozlosnik, Cell-Based Biosensors: Electrical Sensing in Microfluidic Devices, Diagnostics, 2 (2012) 83-96.

[5] U. Hassan, N.N. Watkins, C. Edwards, R. Bashir, Flow metering characterization within an electrical cell counting microfluidic device, Lab Chip. 14 (2014) 1469-1476.

[6] X. Cheng, Y.S. Liu, D. Irimia, U. Demirci, L. Yang, L. Zamir, W.R. Rodríguez, M. Toner, R. Bashir, Cell detection and counting through cell lysate impedance spectroscopy in microfluidic devices, Lab Chip. 7(6) (2007) 746-55.

[7] S. Gawad, L. Schild, P. Renaud, Micromachined impedance spectroscopy flow cytometer for cell analysis and particle sizing, Lab Chip., 1 (2001) 76-82.

[8] A.C. Sabuncu, J. Zhuang, J.F. Kolb, A. Beskok, Microfluidic impedance spectroscopy as a tool for quantitative biology and biotechnology, Biomicrofluidics, 6(34103) (2012) 1-15.

[9] B. Pejcic, R. De Marco, Electrochim. Acta, Impedance spectroscopy: Over 35 years of electrochemical sensor optimization, 51 (2006) 6217- 6229.

[10] J. Wegener, C.R. Keese, I. Giaever, Electric cell-substrate impedance sensing (ECIS) as a noninvasive means to monitor the kinetics of cell spreading to artificial surfaces, Exp. Cell Res., 259 (2000) 158-166.

[11] C. Caviglia, K. Zór, S. Canepa, M. Carminati, L.B. Larsen, R. Raiteri, T.L. Andresen, A. Heiskanen, J. Emnéus, Interdependence of initial cell density, drug concentration and exposure time revealed by real-time impedance spectroscopic cytotoxicity assay, Analyst 140(10) (2015) 3623-3629.

[12] Q. Liu, C. Wu, H. Cai, N. Hu, J. Zhou, P. Wang, Cell-Based Biosensors and Their Application in Biomedicine, Chem. Rev., 114 (12) (2014) 6423-6461.

[13] A. Montrose, S. Cargou, F. Nepveu, R. Manczak, A.M. Gué, K. Reybier, Impedimetric immunosensor for the detection of circulating pro-inflammatory monocytes as infection markers, Biosens. Bioelectron. 49 (2013) 305-311.

[14] Reybier K., Ribaut C., Coste A., Launay J.P., Fabre P.L., Nepveu F., 2010. Biosens. Bioelectron. 25(12), 2566-72. 
[15] J.W. Judy, Microelectromechanical systems (MEMS): fabrication, design and applications, Smart Mater. Struct., 10 (2001) 1115-1134.

[16] G. Justin, S. Finley, A. Abdur Rahman, A. Guiseppi-Elie, Biomimetic hydrogels for biosensor implant biocompatibility: electrochemical characterization using micro-disc electrode arrays (MDEAs), Biomed. Microdevices, 11(1) (2009) 103-105.

[17] T.H. Park, M.L. Shuler, Integration of cell culture and microfabrication technology, Biotechnol. Prog., 19 (2003) 243-253.

[18] W. Franks, I. Schenker, P. Schmutz, A. Hierlemann, Impedance characterization and modeling of electrodes for biomedical applications, IEEE Trans. Biomed. Eng. 52 (2005) 1295-1302.

[19] Matysik F.M., Meister A., Werner G., Electrochemical detection with microelectrodes in capillary flow systems, Anal. Chim. Acta, 305 (1995) 114-120.

[20] D.W. Greve, X. Huang, D. Nguyen, M.M. Domach, Modeling of impedance of cell-covered electrode, Proceedings of the IEEE Sensors 2003 (IEEE Cat. No. 03CH37498), 2 (2003) 1358-1363.

[21] Y. Huang, B. Rubinsky, Sens. Actuat. A-Phys., Microfabricated electroporation chip for single cell membrane permeabilization, 89(3) (2001) 242-249.

[22] S. Cho, H. Thielecke, Physiol. Meas., Design of electrode array for impedance measurement of lesions in arteries, 26(2) (2005) S19-S26.

[23] D.T. Price, A.R. Rahman, S. Bhansali, Design rule for optimization of microelectrodes used in electric cell-substrate impedance sensing (ECIS), Biosens. Bioelectron. 24(7) (2009) 2071-2076.

[24] R. Courson, S. Cargou, V. Conedera, M. Fouet, M.C. Blatche, C.L. Serpentin, A.M. Gue, Low-cost multilevel microchannel lab on chip: DF-1000 series dry film photoresist as a promising enabler,. RSC Adv., 4 (2014) 54847.

[25] C.E. Nwankire, A. Venkatanarayanan, T. Glennon, T.E. Keyes, R.J. Forster, J. Ducrée, Label-free impedance detection of cancer cells from whole blood on an integrated centrifugal microfluidic platform, Biosens. Bioelectron., 68 (2015) 382-389

[26] O. Ordeig, J. Del Campo, F.X. Munoz, C.E. Banks, R.G. Compton, Electroanalysis Utilizing Amperometric Microdisk Electrode Arrays, Electroanal., 19 (2007) 1973-1986.

[27] S.O.P. Blume, R. Ben-Mrad, P.E. Sullivan, Characterization of coplanar electrode structures for microfluidic-based impedance spectroscopy, Sens. Actuat. B-Chem., 218 (2015) 261-270.

[28] N. Couniot, D. Flandre, L.A. Francis, A. Afzalian, Signal-to-noise ratio optimization for detecting bacteria with interdigitated microelectrodes, Sens. Actuat. B-Chem., 189, (2013) 43-51. 
